\title{
Nicaragua 1979-2007. Transición a la democracia y perspectivas de su consolidación ${ }^{1}$
}

Jorge Rovira Mas

Instituto de Investigaciones Sociales de la Universidad de Costa Rica (IIS-UCR). Dirección: Apartado postal 290, San Pedro de Monte de Oca 2050, Costa Rica. Correo electrónico: jrovira@racsa.co.cr

A TRAVÉS DE ONCE PROPOSICIONES EL AUTOR ABORDA DE MANERA sucinta el tema de la transición a la democracia representativa del caso de Nicaragua entre los años 1979 y 1990. Explora los factores de consolidación de la democracia que han estado presentes a partir de inicios de la última década del siglo XX y analiza sus progresos, estancamientos o cursos regresivos. Las primeras cuatro proposiciones se refieren al proceso de transición a la democracia representativa; las siguientes, al de consolidación.

Palabras clave: democracia-Nicaragua / transición / consolidación

\section{Introducción}

Desde una perspectiva tanto teórica como histórica, ¿a cuál o a cuáles tipos de transición a la democracia representativa ${ }^{2}$ pertenece el caso de Nicaragua entre los años 1979 y 1990? ¿Cuáles son los factores de consolidación de la democracia que han estado presentes a partir de inicios de la última década del siglo XX y cómo han evolucionado? ¿En cuáles de ellos se evidencian progresos, estancamientos o cursos regresivos?

Las anteriores son las preguntas que abordo sucintamente en este artículo. Debe aclararse, no obstante, que este análisis no alcanza aún, de modo sistemático, al emergente tema de la calidad de la democracia, incipiente todavía pero que se constituye influenciado por los avances, e igualmente por las limitaciones, que el paradigma de la transición a la democracia y su consolidación aportó en las precedentes dos décadas. Pese a todo, algunos señalamientos acotados sobre el particular se insinúan.

Con el propósito de lograr mayor claridad y precisión, al mismo tiempo que brevedad expositiva, lo he estructurado a manera de proposiciones o tesis concisamente desarrolladas, seguidas al final por otras que son derivaciones principales. Las primeras cuatro se refieren al proceso de transición a la democracia representativa; las siguientes, al de consolidación; los corolarios lo son en perspectiva de conjunto. 


\section{Proposiciones}

\subsection{Primera proposición}

En la literatura teórica sobre los procesos de transición a la democracia, se han identificado cuatro tipos, a saber: los desplazamientos, las transformaciones, los traspasos y las intervenciones ${ }^{3}$.

Es una especificidad, que he resaltado, de algunos de los casos centroamericanos (Nicaragua y El Salvador) de transición a la democracia en este periodo de la tercera ola democratizadora (1974 en adelante), el que sus transiciones a la democracia revistan una mayor complejidad (Rovira-Mas, 1993:156-161; 2002:29-46) y requieran ser conceptuados con base en varios tipos.

Una peculiaridad de la transición a la democracia en Nicaragua consiste entonces en que se compone de dos procesos diferentes. Ellos remiten, conceptualmente, a dos tipos distintos, particularidad que ha sido pasada por alto en la literatura que ha analizado las transiciones hacia este régimen político en la región centroamericana (y en otros casos de otras partes también, como en algunos de África). En concreto, éstos son: el desplazamiento (la expulsión de Somoza en 1979) y el segundo es del tipo traspaso, concretado como acuerdo interelitario entre la cúpula sandinista y el gobierno de Violeta Barrios viuda de Chamorro, tras la derrota electoral de los primeros en febrero de 1990.

\subsection{Segunda proposición}

El primero de ellos, como ha sido lo usual en los desplazamientos como un tipo de transición, se compuso de tres fases diferenciadas:

La primera consistió en la lucha contra Somoza como cabeza del régimen político no democrático de tipo tradicional en su variante patrimonialista de sultanato (Weber, 1964:185), en cuyo interior no había elementos democratizadores o reformistas decisivamente influyentes. Esa fase se caracteriza porque, hacia el final de los años setenta del siglo XX, se fue conformando dificultosamente una amplia coalición de fuerzas sociales y políticas antisomocistas cuyo liderazgo efectivo fue ganando el Frente Sandinista de Liberación Nacional (FSLN), el único actor desde siempre persuadido de que a Somoza sólo se le expulsaría del poder mediante las armas.

La segunda fase comprendió la intensificación de la guerra, la huida de Somoza y el desplome de la Guardia Nacional tras las pretensiones de Urcuyo Maliaños de perdurar en el poder, todo lo cual condujo a una derrota sin concesiones en julio de 1979. Se trató de un resultado mucho más favorable al FSLN de lo que esta misma organización consideraba factible lograr y el último en el que pensaba Estados Unidos al pretender, por diversos medios diplomáticos, limitar los alcances de la entonces inevitable e inminente victoria sandinista.

La tercera fase radicó en la pugna que tras el triunfo se desarrolló en el seno de la coalición antisomocista por la hegemonía dentro de ella. Derivó hacia la preeminencia 
política del FSLN y hacia el intento, muy limitado, de avanzar en su proyecto histórico, caracterizado en sus metas últimas por una sociedad socialista inspirada por el modelo de Cuba, pero teniéndose que privilegiar, en virtud de las circunstancias históricas, el proyecto táctico (economía mixta, pluralismo político y no-alineamiento). A su vez, la oposición política interna, de variado signo ideológico, no logró detener la supremacía sandinista, hasta que una parte de ella, más bien muy tempranamente y en esto azuzada por el gobierno de Estados Unidos, renunció al intento de la competencia política dentro de Nicaragua y constituyó la Contra en su diversidad, con amplio respaldo norteamericano de la administración Reagan (1981-1989), el desarrollo de una guerra de baja intensidad por parte de la Agencia Central de Inteligencia (CLA) y el desgaste del gobierno sandinista en lo económico y en lo político. Los sandinistas ganaron genuinamente las elecciones de 1984, con lo que validaron su legitimidad por la vía del método electoral, pero en el contexto de la agresión de la Contra fueron reduciendo el espacio político de disensión interna, tanto formal como informalmente, y se fueron inclinando por una dinámica semiautoritaria en el ejercicio del poder. En la oposición interna sobresalieron, por encima de los variopintos y numerosos pequeños partidos políticos de limitada base social, el Consejo Superior de la Empresa Privada (COSEP), la alta jerarquía de la Iglesia Católica y el diario La Prensa.

\subsection{Tercera proposición}

El segundo proceso que es, desde el punto de vista teórico, un tipo de transición, pero que complementa al desplazamiento en la compleja trama del cambio de régimen hacia la democracia representativa en Nicaragua, es el traspaso ocurrido en lo fundamental durante el año 1990 pero que se prolongó por un tiempo más. Los traspasos ocurrieron durante la tercera ola democratizadora en situaciones de empate político entre las fuerzas gubernamentales y la oposición, y luego del reconocimiento de ambas partes de los riesgos e incertidumbres implicados en la continuación del conflicto. Sus fases en Nicaragua fueron las siguientes:

La primera fue el inicio de una cierta liberalización del espacio político interno por parte del gobierno sandinista a partir de 1988, un espacio que se había ido menoscabando significativamente conforme avanzaron los años ochenta. Dicha liberalización se acentuó en 1989 tras la decisión de adelantar las elecciones nacionales y pasarlas de noviembre de 1990 a febrero de este año. A todo esto contribuyó la grave situación económica interna que se vivía en Nicaragua como producto de la guerra y del acoso de Estados Unidos por interpósita mano; la imposibilidad evidenciada por el Ejército Popular Sandinista (EPS) de expulsar definitivamente a la Contra; pero sobre todo fue un factor muy influyente el Acuerdo de Esquipulas II, de agosto de 1987, entre los presidentes centroamericanos y sus implicaciones nacionales para la búsqueda de soluciones a las pugnas políticas internas existentes en varias de estas sociedades.

La segunda fase conllevó la campaña electoral y las elecciones de 1990, unas típicas elecciones de apertura 4 (Lamounier, 1984; López-Pintor \& Nohlen, 1993). En estas elecciones, el FSLN experimentó su primera, inesperada e incuestionable derrota electoral frente a la Unión Nacional Opositora (UNO), coalición antisandinista que se desmembraría casi inmediatamente después de su victoria. 
La tercera fase la constituyeron los acuerdos interelitarios entre el FSLN y el gobierno de Violeta Barrios viuda de Chamorro, acuerdos a muchos de los cuales se opuso una parte de la UNO. Esta fase se tornó crucial para la forja de una de las condiciones iniciales de existencia de la democracia representativa en contextos transicionales: la aceptación de la democracia por las élites en contención con mayores recursos de poder, bien que lo hagan por primera o secundaria preferencia. Por un lado, los sandinistas admitían su derrota y, dada la extraordinaria supervisión internacional del proceso electoral y las implicaciones que se derivaban de él en términos de la legitimidad del gobierno, tuvieron que entregarlo y pasarse a la oposición en la mejor tradición democrático representativa. Sin embargo, para ello y para asegurarse una base de reproducción material, y gracias a los recursos políticos que mantuvieron, realizaron la denominada Piñata ${ }^{5}$ con las propiedades tomadas durante el periodo de vigencia de la hegemonía sandinista, procurando garantías con tal fin con el gobierno de Barrios mediante el Protocolo de Transición del Poder Ejecutivo (PTPE). Un componente clave del acuerdo entre estas élites fue la preservación, más allá de cualquier nueva denominación, del Ejército Popular Sandinista con un perfil redimensionado, pero comandado aún por Humberto Ortega y los cuadros jerárquicos entonces al frente suyo.

Este protocolo fue un típico pacto interelitario que a la postre sentaría las bases para que las élites políticas del país, sin excepción, fueran aceptando la competencia electoral como el único procedimiento legítimo, the only game in town (Linz, 1990), para hacerse con el poder del Estado. Barrios, quien carecía de un núcleo partidario fuerte tras sí y con sectores dentro de la UNO que clamaban por una revancha en contra de los sandinistas y por una pronta solución a su favor del problema de la propiedad -a todo lo cual se agregaba la existencia de grupos aún alzados en armas- estableció durante una parte de su gobierno diversos entendimientos con el FSLN. De esta manera no arriesgó el proceso de institucionalización de la democracia y pudo hacer avanzar sus planteamientos económicos neoliberales, en lo que puede calificarse como un astuto y hábil juego político de la élite gobernante en conjunción con el FSLN con implicaciones históricas de largo plazo. Este pacto interelitario poseyó un rasgo característico de los acuerdos que se orientan a institucionalizar la democracia como método para la competencia política: aseguró a las principales élites en conflicto que sus intereses fundamentales estarían a buen recaudo (Peeler, 1998).

Esta modalidad de transición del tipo traspaso reverdeció así, como luego se verá, una acendrada tradición de las élites políticas nicaragüenses y de su cultura política, la que luego del año 2000 volvería a encimar viejos alcances. Se trata de los pactos interelitarios, a veces facilitados por vínculos familiares, que en el caso de Nicaragua comportan el conflicto acentuado y persistente entre dichas élites, por un lado, y los acuerdos o pactos muy amplios, por otro, para compartir el poder y distribuirse oportunidades de diversa índole a la sombra del control o de la influencia privilegiada sobre el Estado, al cual se le percibe como botín.

\subsection{Cuarta proposición}

Tras el traspaso y el cierre de la transición en Nicaragua, la élite dirigente del FSLN vive con una contradicción en su seno que es, sin embargo, funcional para el mantenimiento del régimen político de la democracia representativa. Consiste en lo siguiente: en esa tradición muy arraigada y prolongada de la cultura política en la historia de Nicaragua, 
de índole pactista entre las élites, la dirigencia del FSLN y muchos de sus cuadros más prominentes pasaron a asegurar propiedades de fincas y empresas, y a garantizarse tal condición de propietarios, con lo que adquirieron una base material que les permitiría constituirse en un empresariado con intereses en la preservación del orden social vigente, al mismo tiempo que les creaba condiciones mediante las cuales contar con recursos para no tener que abandonar la lucha política.

Los sandinistas a partir de entonces renunciaron a ser los revolucionarios empeñados en su proyecto histórico, pretendidamente trastocador del orden social prevaleciente en el país. Sin embargo, al mismo tiempo, si a algún sector el sandinismo puede representar en Nicaragua es a ese complejo mosaico que constituyen los sectores populares, en donde se encuentra su base social primera y más importante, y en donde el FSLN acumula lealtades partidarias históricas en tanto que organización política. Pese a esto, es innegable también que con el paso de los años se ha ido haciendo presente en esos grupos sociales la desilusión moral y política frente a ese liderazgo partidario ahora advenido a empresariado, e interesado, sin la menor duda, en la preservación del statu quo.

El resultado ha sido el siguiente: un FSLN que no cuestiona ya ni al capitalismo ni a la democracia representativa, antes bien se encuentra comprometido con ellos. Pero de igual modo, para tener algún grado de vigencia política real y no espuria, representan todavía a un sector de la sociedad que nunca hasta 1979 había alcanzado representación política con vocación efectiva de gobierno (Martí i Puig, 1997:223-226). Para este sector, en el sandinismo se encuentra su vehículo histórico para alcanzar, en algún grado, la expresión de sus intereses, todo lo cual se realiza, ahora sí, sin un cuestionamiento a fondo de las coordenadas socioeconómicas básicas de la sociedad nicaragüense y, más aún, en el marco del régimen político de la democracia representativa.

\subsection{Quinta proposición}

Completar el proceso de transición a la democracia representativa no garantiza la consolidación de este régimen político. Ha de entenderse por una democracia representativa consolidada, desde un punto de vista teórico, aquel régimen dentro de una sociedad "en el cual ninguno de los principales actores políticos, partidos o intereses organizados, fuerzas o instituciones, consideran que hay alguna alternativa a los procesos democráticos para obtener el poder [...] Esto no significa que no haya minorías prestas a desafiar y a cuestionar la legitimidad de los procesos democráticos por medios no democráticos. Significa que los actores principales no recurren a ellos y que esos permanecen políticamente aislados [...]" (Linz, 1990:29).

La consolidación de la democracia representativa constituye un proceso que no debe entenderse como inevitable, pues pueden darse en él progresos, retrocesos y estancamientos. Más aún puede llegarse, bajo ciertas circunstancias, a un colapso de la democracia y a un retorno a regímenes autoritarios o semiautoritarios.

El estudio de la dinámica inicial del proceso de consolidación de la democracia en Centroamérica conviene hacerse entonces concentrando la atención en algunos factores 
de consolidación democrática, que para el caso centroamericano privilegio los siguientes (Rovira-Mas, 2000, 2002): 1- El compromiso democrático de las élites políticas y el buen funcionamiento de las instituciones electorales. 2- La dinámica de subordinación de la institución militar al poder civil legalmente constituido. 3- El proceso de estructuración del sistema de partidos y su capacidad para canalizar el conflicto sociopolítico. 4- Los clivajes ${ }^{6}$ étnicos allí donde los hay y su integración al sistema político del Estado Nacional. 5- Las características adquiridas por la cultura política y su funcionalidad respecto a la reproducción de la democracia. 6- El movimiento que sigue la economía -en particular el crecimiento económico, la pobreza y la distribución del ingreso- que, vía la valoración de la ciudadanía sobre los rendimientos del régimen político -su eficacia-, afecta indirectamente la legitimidad de dicho régimen en el largo plazo.

\subsection{Sexta proposición}

En lo concerniente al primer factor complejo de consolidación democrática, vemos lo siguiente:

En cuanto al compromiso de las élites políticas con la democracia electoral como el único recurso legítimo para la competencia por el poder del Estado y la desestimación del recurso a las balas para acceder a él (en la alternativa entre votos o balas), Nicaragua durante los años noventa mostró progresos, una vez que se resolvieron los conflictos residuales (producto de distintos grupos de alzados y realzados en armas) tras la entrega del poder a Barrios por los sandinistas. No parece haber en el horizonte de la vida política nicaragüense ninguna alternativa antirrégimen significativa.

De igual modo, los resultados de las elecciones nacionales de noviembre de 1996, 2001 y 2006 fueron aceptados por todos los participantes, si bien en las de 1996 se presentaron circunstancias que fueron objeto de algunos cuestionamientos por el FSLN, que al final tuvo que reconocer el triunfo de la Alianza Liberal (AL) con Arnoldo Alemán a su cabeza. Nicaragua ha presenciado desde 1990 cuatro cambios de gobierno consecutivos (1990, 1997, 2002 y 2007), todos entre autoridades civiles electas en procesos considerados libres y competitivos. En dos de ellos además, el gobierno ha sido entregado a la oposición triunfante de inequívoco signo ideológico diferente y contrapuesto (1990 y más recientemente en 2007), lo que constituye no sólo muestras de alternancia sino también un indicador de consolidación democrática.

Reconocido lo anterior, es necesario señalar que eso representa, en la perspectiva histórica de la larga duración en Nicaragua, un avance hacia la consolidación de este régimen político como el único legitimado para la competencia por el poder estatal, pero un avance que se ha constituido como una resultante histórica no necesariamente deseada así en primera instancia por los actores más sobresalientes. Las resultantes históricas son los productos institucionales y de prácticas que devienen como fruto del conflicto y de la contraposición de proyectos e intereses, pero que rara vez responden a la preeminencia impositiva, sin resistencia influyente, de un solo grupo o sector presente en el contencioso. 
Hay que puntualizar entonces que las dos élites más importantes en una década (a partir de 1997, cuando asumió Alemán el nuevo gobierno de manos de Barrios), la del Partido Liberal Constitucionalista (PLC, que era el sector hegemónico dentro de la victoriosa AL), comandado por aquel, y la del FSLN, encabezado por Daniel Ortega, se encuentran comprometidas con la vigencia de la democracia en virtud de la situación histórica, del contexto internacional, de los balances de fuerza en el ámbito interno, y de los intereses elitarios, económicos y políticos, que ambas se encuentran cada vez más interesadas en preservar.

Pero ambos grupos se inclinan asimismo por prácticas que erosionan la legitimidad de instituciones y de actores del régimen político a mediano plazo. Han procurado la constitución de un bipartidismo cuya mecánica competitiva es de naturaleza colusiva, orientado a lo siguiente: 1) A repartirse la influencia sobre las instituciones del Estado y a compartir la dominación política general. 2) A crear, modificar o manipular las reglas de la competencia política para asegurar sus posiciones e impedir la llegada a la arena electoral de terceros contendientes, de modo de reproducir y prolongar su supremacía con el menor riesgo posible a largo plazo. 3) A garantizarse los beneficios, legales e ilícitos, que pudieran derivarse de dicho dominio compartido sobre el Estado y sus instituciones. Todo ello con un débil control de la sociedad y de las entidades estatales pertinentes, a las cuales no sólo no les ha interesado fortalecer sino que, antes bien, han procurado debilitar en algunos casos. De este modo ratifican la enraizada práctica presente en la vida política de Nicaragua del abuso desmedido que ejercen sobre el Estado, y finalmente sobre la sociedad, las élites políticas más descollantes, nada más que ahora en función de dos actores primordiales que compiten entre sí mediados por los procedimientos electorales, no violentos, para conseguir el poder estatal.

En materia del funcionamiento de las instituciones electorales, éstas patentizan dos momentos principales. El primero fue aquel durante el cual fueron organizadas y disfrutaron de una elevada credibilidad. Estuvieron dirigidas entonces por el Dr. Mariano Fiallos O. (1984-1996). No sólo el Consejo Supremo Electoral (CSE) fue creado como otro poder del Estado (1984), así sancionado en la Constitución Política de 1987, y el propio gobierno sandinista, seguro de su arraigo popular para las elecciones de 1984 y de 1990, le brindó un soporte material razonable en medio de las difíciles circunstancias económicas de esos años, sino que también el CSE dispuso entonces del respaldo de instancias internacionales que coadyuvaron a que se organizara con alcance nacional y con un nivel operativo satisfactorio para atender sus tareas fundamentales. A todo esto se le agregó la autonomía del Dr. Fiallos y la respetabilidad de que gozaba entre los diversos actores políticos internos, todo ello jugando a favor de la credibilidad de la institución entre los principales contendientes de aquellos tan importantes primeros comicios electorales.

El segundo momento -fruto de la nueva correlación de fuerzas políticas en la Asamblea Nacional tras la segunda derrota sandinista de 1996, pero principalmente tras el Pacto de enero del $2000^{7}$ entre Alemán y Ortega- se ha venido caracterizando por una excesiva partidización del CSE. Ésta se ha producido con base en los acuerdos políticos entre las dos cúpulas de los partidos principales, orientados al control bipartidista de varias instituciones del régimen político mediante la selección compartida de sus miembros, el CSE una de ellas. Una de las consecuencias recientes más ominosas de esta situación se condensa en la 
inhibición, a partir de manipulaciones legales amañadas con significado político de fondo, de cuatro partidos alternativos a los dos principales que ha dictado el CSE con miras a las elecciones municipales de noviembre de 2008. Entre éstos se encuentra el Movimiento de Renovación Sandinista (MRS, 1995), que hubiera tenido buenas probabilidades de ganar la importante alcaldía de Managua, y el Partido Conservador (PC), con otro tanto de buen ambiente en Granada.

Si el primer momento del CSE coadyuvó a la consolidación de la democracia, durante el segundo está ocurriendo exactamente lo contrario en virtud del descrédito en el cual está cayendo el organismo electoral.

\subsection{Séptima proposición}

Nicaragua, en la dinámica de subordinación de la institución militar al poder civil, es el país que ostenta el mérito, en el conjunto de países centroamericanos comprometidos con la transición a la democracia a partir de 1979-1980 (Nicaragua, Honduras, El Salvador y Guatemala), de ser el que evidencia más progresos.

Las manifestaciones más relevantes de lo anterior han sido las siguientes:

Por primera vez en toda su historia, el país estableció, en el transcurso de la década de los años noventa, un ejército nacional, subordinado al poder civil salido de las urnas electorales, una vez que se fue desmovilizando a los distintos grupos de alzados. El surgimiento del Ejército de Nicaragua (ya no el Ejército Popular Sandinista, EPS, ni la Guardia Nacional de Somoza, tampoco los ejércitos de los líderes liberales o conservadores de antaño) como "nacional, de carácter profesional, apartidista, apolítico, obediente y no deliberante" (artículo 93 de la Constitución Política, a partir de las reformas de 1995), ha estado orientado primordialmente a dejar atrás su partidismo histórico recurrente, sin obviar el hecho insoslayable de que la cúpula castrense proviene aún de los mandos sandinistas. Una situación en apariencia contradictoria, fruto de las correlaciones de fuerzas, que sin embargo ha ido fortaleciéndose en la dirección indicada por la Constitución.

Se han sancionado también apropiados marcos legales, como las reformas a la Constitución de 1995 -mencionadas antes en parte- y la aprobación de la Normativa Interna Militar, entre otros. Las funciones del Ejército fueron redefinidas en términos constitucionales de la siguiente manera: prioritariamente, "la defensa de la soberanía, de la independencia y la integridad territorial" del Estado de Nicaragua, aunque la Constitución le permite cooperar con la Policía Nacional en casos extremos. Posteriormente a lo establecido constitucionalmente, se le han abierto espacios legales para que coopere en la lucha en contra del narcotráfico, con competencias de defensa civil en el caso de desastres naturales $\mathrm{y}$, finalmente, se le atribuyen tareas de apoyo y colaboración en los planes que elabora el gobierno sobre salud y educación, así como en la protección y conservación del medio ambiente.

En 1994, avanzada la administración Barrios (1990-1997), se aprobó el Código de Organización, Jurisdicción y Previsión Social Militar con el objetivo de contribuir a la 
profesionalización de las fuerzas armadas. Doña Violeta llamó a retiro al General Humberto Ortega Saavedra al frente de ellas, para hacerla efectiva en 1995, cuando el clima político nacional se había estabilizado. Desde entonces, la sustitución del Jefe de las Fuerzas Armadas ha venido ocurriendo de una manera rutinizada (a partir de procedimientos legales bien establecidos): Joaquín Cuadra Lacayo (1995-2000), primero; Javier Carrión (2000-2005), luego; y últimamente, Omar Halleslevens (2005-2010), quienes no pueden durar más de cinco años en dicho cargo. Cierto es que todos ellos son ex miembros del EPS, dada la permanencia en el Ejército, que no era negociable para los sandinistas entre 1990 y 1994 , de los cuadros dirigentes originales que provenían de él. Esto tuvo que ser aceptado por el gobierno de Barrios como parte de un proceso de normalización a largo plazo, el cual estaría fincado en la renovación generacional experimentada por el nuevo ejército conforme pasara el tiempo y se fueran jubilando las generaciones más viejas al cobijo del nuevo Instituto de Previsión Social Militar.

El servicio militar forzoso se eliminó en la Constitución de 1995 (artículo 96).

Se produjo una reducción absoluta del tamaño del Ejército, que pasó de contar con unos 70,000 efectivos hacia 1988 en plena guerra, a tener alrededor de 16,000 cuando concluían los noventas (PNUD, 2003:241), el menor en la región centroamericana, aunque recientemente Halleslevens ha mencionado que su número es de 12,500 (La Prensa, 19 de diciembre de 2006).

Y desde muy temprano, en 1992, se creó el Centro Superior de Estudios Militares, a fin de establecer las condiciones para una formación profesional de los miembros del Ejército que consolidara la carrera militar.

Todos estos eventos y procesos, y su evolución, reflejan progresos importantes en materia de subordinación de los militares al poder civil en una perspectiva de largo plazo ${ }^{8}$.

Persisten, sin embargo, algunos retos pendientes de atender: principalmente lo que se conoce como el control civil subjetivo, es decir, la necesidad de contar con civiles especializados en la cuestión militar que desde las esferas del gobierno y de la Asamblea Nacional coadyuven a consolidar y a supervisar los avances habidos en las nuevas relaciones entre el poder civil y el estamento militar. Y el segundo: el cuidado que deberán tener las autoridades civiles y la propia Asamblea Nacional una vez más, de que las nuevas funciones establecidas constitucionalmente para el Ejército, sobre todo aquellas que se encuentran referidas a programas típicamente civiles, no sean alteradas, ni en sentido ni en alcances, en beneficio de una mayor autonomía e ingerencia de los militares en los asuntos civiles.

\subsection{Octava proposición}

Un factor crucial en todos los procesos de consolidación democrática es la estructuración y el funcionamiento del sistema de partidos políticos. En el marco de un régimen democrático representativo, el sistema partidario constituye el vehículo por excelencia para la canalización del conflicto político, en contraposición al recurso a otras instancias como los diversos órganos represivos, que introducen la violencia además, pero que han sido tan apelados en las sociedades centroamericanas. 
En la situación actual de Nicaragua, a partir del clivaje que significó el desplazamiento de Somoza por los sandinistas, el gobierno de éstos y la guerra en el interior del país organizada en su contra con el patrocinio de Estados Unidos, el campo político se ha configurado como bipolar, es decir, un campo disputado entre el sandinismo y el antisandinismo. Y la dinámica que ha seguido la estructuración del sistema de partidos políticos, si bien con la presencia de numerosas organizaciones de distinto tamaño, ha propendido, en cuanto a su formato, hacia el bipartidismo con polarización ideológica ${ }^{9}$.

Paradójicamente, dicha bipolaridad sandinismo-antisandinismo, que ha jugado a favor de una estructuración consistente y duradera de las lealtades partidarias (y de la retórica que la acompaña para el combate electoral, así como para la reafirmación entonces de esas identificaciones con los partidos principales), no ha impedido el desarrollo de una mecánica de competencia política entre las élites de índole colusiva. Este es un rasgo específico y capital del actual proceso político nicaragüense.

Efectivamente, ya desde poco después de que Alemán (1997-2002) arribara al gobierno, ambas élites se aproximaron para asegurarse beneficios mutuos de distinta naturaleza. Y lo hicieron aún más cuando concretaron el Pacto de enero del 2000. Tras la llegada a la presidencia del ingeniero Enrique Bolaños (2002-2007), de la misma procedencia partidaria que la de su predecesor, el conflicto por la conducción política del país entre éste y Alemán se enervó. Alemán se había convertido en diputado con base en las reformas legales convenidas en el Pacto y presidía la Asamblea Nacional. Bolaños procuró entonces desacreditarlo y debilitarlo políticamente mediante una supuesta lucha en contra de la corrupción, a partir de lo cual buscó un acercamiento con el FSLN, pero sin percatarse hasta cuál punto las prácticas alemanistas de burdo, chocante pero eficaz clientelismo habían penetrado en el liderazgo del PLC y lo habían corroído. La intención de Bolaños era deshacerse de Alemán apelando a la ayuda que podría brindarle su enemigo histórico, Ortega y el FSLN, pero no alcanzó su objetivo. A pesar del desafuero de Alemán, del juicio en su contra por una venalidad reconocida, y del veredicto favorable a su encarcelamiento por unos tribunales influidos por el FSLN, las consecuencias fueron distintas a las ansiadas por Bolaños. De una parte, en dicho conflicto el FSLN adquirió un nuevo poder de intermediación privilegiada entre los dos sectores de la familia del liberalismo, así como de chantaje sobre el destino del líder del PLC -si cárcel de verdad o de mentirillas, como ha estado sucediendo-, quedando Alemán a merced de Ortega y de algunas de sus exigencias, mientras que Bolaños veía cómo avanzaba su mandato con recursos de poder de alcance limitado y con logros modestos. Pero lo más descollante es que ambos liderazgos, el del FSLN y el del PLC, han quedado atrapados en una relación colusiva y perversa para la democracia nicaragüense y su calidad de funcionamiento.

En suma, este vínculo ha venido resultando mutuamente ventajoso para que el PLC y el FSLN se aseguren el control sobre el sistema político nicaragüense, pero en detrimento de la calidad de la vida pública en Nicaragua, envilecida por el deterioro de las instituciones, la corrupción y la impunidad, como prácticas propensas a aceptarse como antivalores normales inherentes a ella. Cogobierno, el Estado como botín, y la corrupción como medio para el actuar político y como recurso para lograr el enriquecimiento indebido, exacerbado esto último en especial cuando se piensa en la figura de Alemán y en el PLC, sintetizan mucho de la mecánica resultante vigente en el sistema de partidos políticos. 
Por otra parte, las elecciones de 2006 trajeron la novedad de que se agregara, a la división del sandinismo (FSLN-MRS), la fractura del antisandinismo. Estos se escindieron en dos organizaciones: el PLC con José Rizo como su candidato (27.1\% de la votación), y la Alianza Liberal Nicaragüense (ALN) que postuló a Eduardo Montealegre (28.3\%), candidato de un sector influyente del empresariado y de la Embajada de Estados Unidos en Nicaragua. Una postulación concretada para configurar una alternativa antisandinista distinta al alemanismo y sus prácticas clientelistas y corruptas. Esta escisión contribuyó de modo decisivo a la victoria del FSLN (con un ajustado 38\% de los votos, porcentaje menor que el obtenido en las del 2001), una vez que mediante el Pacto del 2000 se redujera el valor de la regla de mayoría para alcanzar la presidencia en primera vuelta (véase la nota 7). Mientras que el FSLN ha retornado a la presidencia, Alemán tiene que haberse complacido al observar un resultado que ha alejado del poder gubernamental a sus ahora enconados enemigos de adentro de su propia familia partidaria, la liberal, una parte de la cual podría no ser con él tan condescendiente como lo ha venido siendo Ortega.

Por su parte, el gobernante FSLN enfrenta por fin el reto de atender, al menos en alguna medida, las demandas que vienen de sus bases sociales y las ofertas desproporcionadas que en su afán de victoria le propuso a los electores en el 2006. Más allá de su apuesta segura por el statu quo económico y político, con el que tanto medran sus cuadros dirigentes y algunas de las nuevas élites económicas hoy adláteres del sandinismo, lo cierto es que no le bastará con su retórica para conseguir reafirmar hacia el futuro las identificaciones partidarias, si bien decrecientes, pero que de tanto le han valido. Con ellas ha contado por más de tres lustros, incluso sin alcanzar el gobierno y sin que le hubiera sido necesario probar su bona fide y una eficacia razonable en el manejo de la cosa pública, con efectos claramente sensibles sobre la situación de los sectores populares. Pero ahora le llegó su turno, ese al que Marx aludía en El Capital cuando recordaba la fábula de Esopo y exigía "hic Rhodus, hic salta” (aquí está Rodas, salta aquí, pues).

De este modo, se está produciendo en Nicaragua una cierta paradoja. De una parte, el que sean los partidos y el sistema de partidos en su conjunto, en un marco competitivo vía el método electoral, los que desempeñen el papel institucional más relevante en la competencia política, y no otras instancias o actores como los militares por ejemplo, constituye un progreso y apuntala la consolidación de la democracia. Pero, por otra, las consecuencias de la mecánica competitiva colusiva que han venido institucionalizando el FSLN y el PLC, que genera descrédito a los partidos y a los políticos, hace que éstos sean escasamente considerados como los representantes adecuados de los intereses y las aspiraciones de los ciudadanos (Rodríguez \& Madrigal, 2005:155 y ss., especialmente 162-163) .

\subsection{Novena proposición}

En materia de clivajes étnicos, en general suaves en Nicaragua y de ninguna manera comparables con los que experimenta, por ejemplo, la sociedad guatemalteca, fueron más bien los sandinistas los que contribuyeron a exacerbarlos a inicios de la década de los años ochenta entre los pobladores de la Costa Atlántica y el poder central. Fueron también aquéllos los que le buscaron una solución que al final resultó en la aprobación en 1987 del Estatuto de Autonomía de las Regiones de la Costa Atlántica de Nicaragua. Gracias a él se 
establecieron dos regiones: la Región Autónoma del Atlántico Norte (RAAN) y la Región Autónoma del Atlántico Sur (RAAS). En ambas se han venido eligiendo desde entonces, con la periodicidad correspondiente de cada cuatro años desde 1990, los miembros (45) de cada uno de los consejos regionales, su órgano administrativo regional superior ${ }^{10}$.

Sin embargo, pese a lo anterior, que fue un progreso en algunos sentidos,--entre otros porque institucionalizó la representación política para los distintos grupos étnicos de la Costa y les otorgó formalmente mayor poder y participación sobre sus propios asuntos que aquel con el cual previamente contaban- la realidad es que a partir del gobierno de Barrios (19901997) y no menos durante los de Alemán (1997-2002) y Bolaños (2002-2007), la situación prácticamente no ha mejorado. La debilidad de la propia ley del estatuto de autonomía para garantizar a ésta de mejor manera; la constitución del Instituto para el Desarrollo de las Regiones Autónomas (INDERA) durante el gobierno de Barrios (1991), mucho más vinculado al poder central y con mayores recursos económicos que aquellos de los propios órganos regionales; la difícil situación social y económica en la que se debaten los pobladores de la Costa, por no decir el abandono en el cual se encuentran sumidos; y los valiosos recursos naturales de esas regiones, que estimulan el interés de las empresas foráneas y el de los nacionales del Pacífico, todo ello ha contribuido a un ejercicio precario de la autonomía y a una ingerencia del poder central que mantiene muy insatisfechos a los pobladores de estas regiones y a sus organizaciones políticas.

En resumen y en perspectiva de casi tres décadas, los sandinistas propiciaron durante su gestión una nueva visibilización de la Costa, sobre todo en términos de su potencial económico para el desarrollo del país en su conjunto, pero subestimaron en un inicio las aspiraciones políticas que subyacían a la diversidad cultural de los grupos étnicos presentes en la región. El modus operandi sandinista, también centralista, generó un malestar que la Contra aprovechó y que incrementó las tensiones en todo el Caribe nicaragüense durante la primera parte de la década de los años ochenta. Pero la solución lograda por ellos con el establecimiento de las dos regiones (RAAS y RAAN) en 1987, ha favorecido cierta visibilización política cualitativamente distinta de los grupos costeños y la aparición de algunas organizaciones que los representen (aunque el peso electoral de los partidos nacionales siga siendo allí enorme). Con las dos regiones además se ofreció una respuesta a las siempre latentes inclinaciones separatistas presentes en la costa atlántica nicaragüense y se fortaleció la integración política del Estado Nacional. La incorporación de los grupos sociales de la Costa a la vida política democrática, al menos de un modo un poco más activo $\mathrm{y}$ visible que antes, ha favorecido el alcance territorial de la democracia representativa, no obstante los gravísimos problemas económicos y sociales que aquejan a los pobladores de esas regiones del país y que los condicionan negativamente para el ejercicio de sus derechos políticos.

\subsection{Décima proposición}

Los acuerdos políticos en una democracia representativa entre los liderazgos partidarios son cuestión normal y esperable, parte consubstancial del juego político democrático. Se acepta que no sólo contribuyan a la búsqueda negociada del interés general (que suele vérsele desde cierta óptica particular a partir de la cual es que se interpreta y descifra lo que podría 
ser el bienestar general), sino que también incorporen regularmente intereses específicos que tienen los actores, bien que sea para preservar o para mejorar sus propias posiciones políticas en el marco de la competencia sistémica. Pero hay acuerdos de acuerdos. Los hay también en los cuales los intereses particulares de los actores agotan el intercambio. Y los hay, más aún, en los que dichos intereses sectoriales se concentran en la expoliación sistematizada de las instituciones estatales y en el aprovechamiento para sí de los recursos públicos o de las oportunidades que brinda el poder, a fin de conseguir ventajas privadas y desarrollarlas en perjuicio del interés colectivo. Estos últimos en especial son los que forman parte sobresaliente de la cultura de las élites políticas en Nicaragua, a los cuales se les denomina pactos.

El pactismo de esta naturaleza entre las cúpulas políticas quizás sea el rasgo más prominente y con mayores consecuencias que posee la cultura política nicaragüense. Es un peso del pasado que le ha sido heredado a la democracia representativa vigente, característica que es, quizás, la que más conspira en contra de la valoración de las instituciones y de los actores de este régimen por parte de la ciudadanía en general.

La historia del pactismo en Nicaragua es extensa y no se puede relatar aquí. Baste recordar que no se inaugura con los Somoza, que viene del siglo XIX, pero que ellos también forman parte suya. Fueron actores que portaron y desarrollaron esas maneras de pensar, de sentir y de hacer, esa cultura, forjada en la evolución política de la propia sociedad nicaragüense y labrada por ella. Estas fueron sus contribuciones sobresalientes: el Pacto Sacasa/Somoza García de 1935; el Pacto Somoza García/Cuadra Pasos de 1948; el Pacto Somoza García/ Chamorro de 1950, ampliamente conocido como el Pacto de los Generales (liberal Somoza, conservador Chamorro); y el Pacto Somoza Debayle/Agüero de 1971 (o Kupia-Kumi en miskito, "un solo corazón”). En todos la cuestión central fue la de cómo repartirse el poder, cómo perdurar en él ajenos a la competencia democrática libre y de resultados inciertos, y cómo despojar metódicamente, institucionalizadamente, de recursos y posibilidades al Estado percibido como botín, en perjuicio de la sociedad.

Hay que abonarle a los sandinistas que durante toda la década de los años ochenta, dados los recursos con los que consideraban contar y su vocación política orientada a la hegemonía sin concesiones, no fueron pactistas. Eludieron así por un tiempo la cultura política prevaleciente en su sociedad. Sin embargo, el Protocolo de Transición del Poder Ejecutivo de 1990 entre ellos y el liderazgo que gobernaría en nombre de la UNO, tuvo muchísimo de típico acuerdo interelitario en contextos transicionales hacia la democracia, por un lado, pero también tuvo componentes ya pactistas -quizás la magnitud de la Piñata el más destacable- por otro.

Pero el Pacto de enero del 2000 entre Alemán (portador por excelencia de este aspecto de la cultura política nicaragüense, junto con el clientelismo desembozado en su caso) y Ortega y la cúpula sandinista, con el cual se buscaba asegurar (por medio de componendas y en atropello a la institucionalidad democrática que se iba construyendo) la magnitud de la influencia política de ambos y la impunidad de aquel, es el nuevo ejemplo de cuánto pesa la cultura, cuánto sobrevive el pasado y la tradición en los propios actores durante los procesos de cambio. 
Terminaré señalando que la cultura política del pactismo actúa también en perjuicio de la calidad de la democracia en un marco de incipiente consolidación de este régimen político, cuando precisamente la institucionalización de valores y de prácticas diferentes sería tan importante.

La calidad de una democracia depende en buena medida de la calidad de sus instituciones y de sus actores (élites y ciudadanía organizada). Pero la calidad de las instituciones depende mucho de la de las élites que las producen y que las lideran cuando se encuentran al frente suyo. Y la cultura política, y los procesos de socialización primaria y secundaria que a su reproducción le son inherentes, influyen de manera preponderante sobre la calidad de las élites. Esta es la lógica con la cual funcionan las cosas y cuyos contenidos la sociedad nicaragüense tendría que transformar.

¿Cómo cambiar y superar esta cultura pactista que ha envilecido una dimensión de la vida política del país y que tanto tiende a condicionarla negativamente hacia el futuro? Quizás sea este el principal reto político que confronta la democracia de Nicaragua.

\subsection{Decimoprimera proposición}

Durante las décadas de los años setenta, ochenta y noventa del siglo XX, la sociedad nicaragüense tuvo que enfrentar las siguientes circunstancias adversas: el terremoto de Managua de 1972; la insurgencia que condujo al desplazamiento de Somoza; la crisis económica internacional de finales de los años setenta y primeros de los ochenta; y luego la guerra interior patrocinada por Estados Unidos y el boicot a la economía nicaragüense que ello significó, además del enorme incremento en el gasto de defensa que dicha guerra implicó. No sorprende por ello que durante dos décadas (mediados de los setentas hasta mediados de los años noventa) los indicadores macroeconómicos se deterioraran extraordinariamente (bajísimo crecimiento o incluso crecimiento negativo del producto, exportaciones, deuda externa que llegó a ser inmensa en términos per cápita para una sociedad con una débil economía como la suya, la inflación, el perfil del empleo, los salarios e ingresos reales, el déficit fiscal y otros).

Un problema que no debiera subestimarse para la consolidación de la democracia, es la grave situación socioeconómica que padece la inmensa mayoría de la población del país y los efectos que esto pudiera llegar a tener en términos de incidir, indirectamente, sobre la legitimidad del régimen político.

Si bien el FSLN cuando tuvo que entregar el Ejecutivo dejó el país en una situación económica ruinosa (altísima inflación en primer lugar, deterioro inmenso de los salarios reales, caída de la producción y de la inversión, gigantesca deuda externa, entre otros aspectos), lo cierto es que con la entrada del gobierno de Barrios el cambio en la orientación de la política económica fue radical. Los ortodoxos, en términos neoliberales, establecieron programas de estabilización macroeconómica primero y de ajuste estructural después, si bien tuvieron que enfrentar una importante resistencia social en su inicio, especialmente durante los años 1990 y 1991, la que en parte fue contenida por el propio FSLN en sus arreglos políticos con el nuevo gobierno. 
Algunos de los resultados de esas políticas en el largo plazo han conseguido reproducir una sociedad con un crecimiento económico bajo (menos del 2.5\% anual) durante los inicios de la década pasada, más tarde mediano en algunos años (entre 2.5 y $5 \%$ ), con pobreza generalizada y una desigualdad muy marcada. Debe mencionarse, no obstante, que entre 1995 y el año 2000 el crecimiento anual real del PIB mejoró, aunque a partir de una base absoluta muy baja y endeble. A todo ello habría que agregar el deterioro que inicialmente experimentaron los servicios sociales que brinda el Estado, la reducción de sus alcances y la entronización de la lógica individualista propia del capitalismo, que hace estragos en sociedades muy empobrecidas como ésta, la del "sálvese usted como pueda". Desde entonces, la emigración aumentó enormemente (sobre todo hacia Costa Rica, lo que no sucedió en dicha magnitud, ni mucho menos, durante los años de la hegemonía sandinista) como válvula de escape y de apoyo a los que han permanecido en el país.

El panorama económico y social de Nicaragua en la presente década sigue siendo sombrío, incluso si se le compara con el de por sí penoso horizonte centroamericano. Algunos retazos: el crecimiento económico, como promedio anual en términos reales en lo que va de la presente década (2000-2007) ha sido levemente superior al 3\%, lo que puede considerarse como mediano bajo, es decir, muy modesto para una sociedad como la nicaragüense que tanto necesita crecer para emplear a su población en acelerado ingreso a la etapa productiva y que, según la Comisión Económica para América Latina y El Caribe (CEPAL) "requeriría de un crecimiento sostenido [...] del 6\% anual hasta el 2015" para hacer disminuir la pobreza extrema a la mitad en dicho año (PNUD, 2007:20). Es, tras Haití, el país más pobre de América Latina, con un 46.2\% de población pobre en el 2005 (en relación con el 50\% en 1993); con un 15\% de población en pobreza extrema en el primer año (en 1993, 19.4\%) y con cerca del 70\% de la población rural en la primera condición, también en el 2005 (PNUD, 2007:42). No es de extrañar por ello que uno de cada siete hogares tenga a alguno de sus miembros residiendo fuera del país. El gasto social público per cápita era apenas de USA $\$ 90$ en el 2005, el menor en los 21 países latinoamericanos considerados a este efecto en el estudio, si bien ha crecido un poco desde una base bajísima, pero muy distante de los USA $\$ 772$ de Costa Rica o los USA $\$ 344$ de Panamá, aunque próximo a los USA $\$ 100$ de Guatemala y a los USA $\$ 120$ de El Salvador y Honduras (CEPAL, 2007:106). Y la desigualdad en el ingreso patentizaba una relación de 45 a 1 entre lo que percibía el decil más rico con lo que alcanzaba el decil más pobre con respecto al ingreso total, también hacia el 2005 (PNUD, 2007:42).

Contrario al sentido común, una situación económica y social con grandes déficit y carencias, en la cual no se avanza en su superación con el ritmo que la propia situación demanda, como es la del caso de Nicaragua, no implica el que automáticamente la consolidación de la democracia sea imposible, aunque ciertamente la puede poner en jaque en el largo plazo si se mantuviera tal tendencia. Esto podría suceder en el siguiente sentido: el deterioro socioeconómico afecta la percepción de eficacia gubernamental entre la ciudadanía y ella, si es muy negativa y reiterada a lo largo de distintos gobiernos durante un prolongado periodo, puede llegar a afectar la percepción de legitimidad del régimen político (Lipset, 1988:67-83). Sin embargo, más aún, incluso la disminución en la legitimidad no asegura tampoco, de manera necesaria, la quiebra inminente de la democracia, pero sí, en cambio, contribuye a crear un trasfondo político para que actores antisistema, si los hubiera o si surgieran alentados en parte por tales circunstancias, puedan intentar resquebrajar el 
orden político democrático representativo y contar con una base social de respaldo a su proyecto.

Esta es la conexión entre la situación económica y social, por un lado, y la consolidación de la democracia, por otro, que en el caso nicaragüense despierta justificadas preocupaciones.

\section{Corolarios}

\subsection{Corolario primero}

Una de las contribuciones más importantes del sandinismo a la historia de Nicaragua, en una paradoja notable de cómo funciona ésta y de cómo la acción de los actores produce resultados inesperados y no previsibles, fue su aporte al proceso de institucionalización de la democracia representativa, a pesar de que tal aspiración jamás se encontró en su proyecto histórico.

Vamos a dejar que sea el propio Sergio Ramírez, ex vicepresidente de Nicaragua de la década de los años ochenta, quien confirme este aserto con sus propias palabras en sus memorias de la Revolución Sandinista (Adiós muchachos):

El nuestro fue un régimen muy democrático, en un sentido nuevo, y muy autoritario, en un sentido viejo. Pasados los años, lo que se llamó el proyecto táctico terminó imponiéndose, como ya dije, y la democracia, ya sin apellidos, ni burguesa, ni proletaria, vino a ser el fruto más visible de la Revolución. La gran paradoja fue que, al fin y al cabo, el sandinismo dejó en herencia lo que no se propuso: la democracia, y no pudo heredar lo que se propuso: el fin del atraso, la pobreza y la marginación (Ramírez, 1999:115).

Por otra parte, los sandinistas tampoco han logrado escapar al peso de la peor parte de la tradición política de su sociedad, la de la cultura del pactismo: se han convertido ahora, en asocio con Alemán y el PLC, en los secuestradores de esta democracia que contribuyeron a institucionalizar aunque fuese como su segunda preferencia.

\subsection{Corolario segundo}

La sociedad nicaragüense, en el transcurso del último cuarto de siglo, transitó al régimen político de la democracia representativa y completó dicho proceso mediante un desplazamiento y un traspaso. Se trató de una dinámica inusualmente compleja dentro del universo de las transiciones políticas durante la tercera ola democratizadora.

En cuanto a los factores analizados de consolidación democrática, en los últimos tres lustros los resultados han sido mixtos, evidenciándose progresos en algunos de ellos pero igualmente haciéndose patentes limitaciones y retrocesos en otros.

En relación con el compromiso democrático de las élites y el funcionamiento adecuado de las instituciones electorales, sobresale la institucionalización del método electoral, que ha sido 
aceptado por todos los actores políticos fundamentales para dirimir quién está autorizado por la sociedad para gobernar. Pero al mismo tiempo, el partidismo presente en el CSE en lo que va de la presente década, que está minando la gran credibilidad lograda en sus primeros diez años de funcionamiento, constituye un retroceso para la consolidación de la democracia en Nicaragua.

Un segundo factor de gran relevancia es la subordinación de la institución castrense al poder civil legítimamente constituido. Aquí el progreso ha sido notable, en perspectiva del propio país y del resto de las sociedades de la región centroamericana.

El tercer factor a comentar es el proceso de estructuración que ha seguido el sistema de partidos políticos. Efectivamente, en este punto los resultados de nuevo son mixtos. Mientras que el campo político, como era de esperarse, se ha configurado como bipolar (sandinismo vs. antisandinismo), el sistema de partidos está cumpliendo las funciones capitales que de él se espera para la consolidación de la democracia: ser el vehículo por excelencia para la canalización del conflicto político por medios institucionales no violentos. A su vez, el formato al cual propende el sistema partidario es el de un sistema bipartidista polarizado con una mecánica de competencia colusiva. El problema primordial para la consolidación estriba en esta última característica: las dos formaciones políticas más importantes no dubitan en actuar de consuno para debilitar porciones estratégicas del aparato institucional del régimen democrático, y para desvirtuar los valores y las prácticas de la democracia, todo con el fin de asegurarse un control duopólico del sistema político y una exacción abusiva de los recursos estatales, en el contexto de una sociedad extremadamente pobre y tradicionalmente abusada por sus élites políticas. El Pacto celebrado en el año 2000 entre Alemán (PLC) y Ortega (FSLN), y sus múltiples consecuencias, es la expresión más sobresaliente de esta mecánica colusiva de competencia interelitaria, ahora rediviva.

En cuanto al cuarto factor, el de la resolución favorable de los clivajes étnicos en términos de su integración política dentro de un marco institucional democrático, Nicaragua ha logrado darle una primera solución a la tensión existente entre los pueblos de la Costa y el poder central gracias al establecimiento de las dos regiones autónomas en el atlántico. Pero se trata de una primera solución que demanda desarrollarla muchísimo más en términos económicos, sociales y culturales, en lo que se evidencian rezagos extraordinarios.

El quinto componente, el de la cultura política pactista y sus secuelas perversas, constituye el elemento que más deprime la calidad de la vida democrática y que se confabula a favor del descrédito de la política, de las instituciones y de los actores políticos en la democracia representativa de Nicaragua.

Por último, la situación económica y social, si bien con algunas mejoras levísimas, no estimula el optimismo, dado los déficit tan grandes que arrastra Nicaragua y el ritmo tan lento con el cual se avanza en su atención.

La consolidación de la democracia en Nicaragua tiene un futuro incierto a pesar de los progresos habidos, que son varios y muy valiosos. Tiene por delante desafíos de gran hondura y duración. Son sus actores políticos del día de hoy y los del muy próximo mañana 
los que se encargarán de modelarla como espuria, o bien de ratificar su institucionalización con una calidad superior.

\section{Notas}

1 Este artículo inédito es un producto alcanzado gracias a la labor que su autor despliega en el marco del Instituto de Investigaciones Sociales de la Universidad de Costa Rica (IIS-UCR) y con su respaldo institucional.

2 El concepto de democracia utilizado aquí, se localiza en el marco de la tradición teórica que lo significa con un alcance restringido: como un régimen político cuya institución vertebral es la del sufragio (el método electoral). En él las élites políticas y los partidos desempeñan tareas insoslayables y de primer orden. Esta definición, a la luz del linaje teórico inaugurado por Schumpeter (1942 en inglés, 1946 en español), la teoría pluralista-elitista-competitiva, no agota, ni mucho menos, el debate contemporáneo en torno a la democracia, el cual es extremadamente rico. Pero con ella se precisa el enfoque y el alcance con el cual, en esta oportunidad, se analiza la realidad sociopolítica nicaragüense. Un desarrollo conceptual amplio del paradigma de la transición a la democracia representativa y su consolidación, especificado para los casos centroamericanos, se encuentra en mi artículo del año 2002.

3 Aunque aquí se han utilizado los términos teóricos propuestos por Huntington (1994) con sus características, existe una relativamente amplia coincidencia en cuanto a los tipos señalados, no siempre bajo las mismas denominaciones.

4 Denomínanse elecciones de apertura aquellas que constituyen una pieza clave para el cambio de régimen, bien que sea autoritario o se haya convertido en semiautoritario.

5 Correctamente calificada por Oscar René Vargas como el "proceso de acumulación originaria de capital de los cuadros superiores y medios de la burocracia partidaria y sindical del sandinismo" (1999:144).

6 El término clivaje (cleavage), de significado teórico, alude a las fracturas sociales y políticas que se producen en las sociedades a partir de ciertos procesos de mucha significación. Entre sus consecuencias más persistentes se encuentra la fijación de identificaciones partidarias mediante las cuales es que tienden a estructurarse duraderamente los sistemas de partidos políticos.

7 Ya internado en la segunda mitad de su mandato constitucional, que en enero del 2000 contabilizaba tres de sus cinco años, Alemán buscó darse garantías de diversa naturaleza para asegurar su impunidad y su influencia política tras salir de la Presidencia. El Pacto con Ortega fue amplio y en diversos ámbitos, con beneficios mutuos de índole política: entre distintos logros, ambos se aseguraron el acceso a la Asamblea Nacional, Alemán con curul de ex presidente y Ortega si perdía las elecciones de noviembre del 2001 y el FSLN entraba de segundo; se modificó la regla de mayoría para alcanzar la presidencia sin tener que llevar a cabo una segunda vuelta, reduciéndola hasta un mínimo del $35 \%$ siempre y cuando el partido que alcanzase el segundo lugar quedara distanciado por más del $5 \%$ de los votos con respecto del primero, lo que favorecía al FSLN, dado el techo que había venido caracterizando su desempeño electoral; y se repartieron las posiciones más influyentes en varias entidades gubernamentales o estatales de importancia estratégica para sus intereses, como la Corte Suprema de Justicia, el CSE y la Contraloría General de la República, que luego la emprendería en contra de Bolaños, entre otras.

8 Sobre el tema hay varios trabajos importantes, uno de ellos sobresaliente, el de Roberto Cajina (1996).

9 Para un examen de los tipos de sistemas de partidos, así como de su formato y su mecánica, puede consultarse la importantísima obra de Giovanni Sartori (1980).

10 Un muy buen estudio sobre el tema es el de Carlos M. Vilas (1992). 


\section{Referencias bibliográficas}

CAJINA, R. J. (1996). Transición política y reconversión militar en Nicaragua, 19901995. Managua: CRIES.

CEPAL (2007). Panorama social de América Latina. Santiago de Chile: CEPAL.

HUNTINGTON, S. (1994). La tercera ola. La democratización a finales del siglo XX. Barcelona: Ediciones Paidós.

LAMOUNIER, B. (1984). "Opening through Elections: Will the Brazilian Case Become a Paradigm?”, en Government and Opposition, Vol. 19, No. 2.

LINZ, J. (1990). "Transiciones a la democracia”, en Revista Española de Investigaciones Sociológicas, No. 51, 7-33. Madrid.

LIPSET, S. M. (1988). El hombre político. Buenos Aires: TECNOS-REI Argentina.

LÓPEZ-PINTOR, R. \& NOHLEN, D. (1993). "Elecciones de apertura: El caso de Nicaragua 1990", en Nohlen, D. (Editor), Elecciones y sistemas de partidos en América Latina.

San José de Costa Rica: IIDH-CAPEL, pp. 205-222.

MARTÍ i PUIG, S. (1997). La revolución enredada. Madrid: Los Libros de la Catarata.

PEELER, J. (1998). Building Democracy in Latin America. Boulder, Colorado: Lynne Rienner Publishers.

PNUD (2007). Valoración común de país. Nicaragua 2007. Managua: Impresión Comercial La Prensa.

(2003). Segundo Informe sobre Desarrollo Humano en Centroamérica y Panamá. San José, Costa Rica: EDITORAMA.

RAMÍREZ, S. (1999). Adiós muchachos. México: Aguilar-Altea-Taurus-Alfaguara S.A. de C.V.

RODRÍGUEZ, F. \& MADRIGAL, J. (2005). Paz y democracia. Paradojas de la cultura política centroamericana. San José de Costa Rica: Sección de Impresión del SIEDIN.

ROVIRA-MAS, J. (2002). "Transición a la democracia y su consolidación en Centroamérica:

Un enfoque para su análisis", Anuario de Estudios Centroamericanos, Vol. 28, Nos. 1 y 2, páginas 9-56. San José de Costa Rica.

(2000) "Consolidación de la democracia", en IIDH-CAPEL, Diccionario electoral,

Tomo I. San José de Costa Rica, IIDH-CAPEL, páginas 237-253.

(1993) “DemocraciasemergentesypartidospolíticosenCentroamérica:Consideraciones para su investigación”, en Steichen, R. (Editora), Democracia y democratización en Centroamérica. San José de Costa Rica: Editorial de la Universidad de Costa Rica, páginas 153-171.

SARTORI, G. (1980). Partidos y sistemas de partidos. Madrid: Alianza editorial s.a.

SCHUMPETER, J. (1946). Capitalismo, socialismo y democracia. Buenos Aires: Editorial Claridad.

VARGAS, O. R. (1999). El sandinismo: Veinte años después. Managua: Centro Nicaragüense de Escritores.

VILAS, C. (1992). Estado, clase y etnicidad: La Costa Atlántica de Nicaragua. México: Fondo de Cultura Económica.

WEBER, M. (1964). Economía y sociedad. 2 tomos. México: Fondo de Cultura Económica. 